\title{
Revealing the growth kinetics of atmospheric corrosion pitting in aluminum via in situ microtomography
}

Philip J. Noell (iD ${ }^{1 凶}$, Eric J. Schindelholz ${ }^{1}$ and Michael A. Melia ${ }^{1}$

Understanding the mechanistic relationship between the environment, microstructure, and local kinetics of atmospheric corrosion damage remains a central challenge. To address this challenge, this study used laboratory-based X-ray tomography to directly observe attack in-operando over an extended period, enabling insights into the evolving growth kinetics and morphology of individual pits over months of exposure. Damage progression associated with nine pits in a $99.9 \%$ pure aluminum wire exposed to chloride salts in humid air was characterized. Most pits grew at a nominally linear rate up until pit death, which occurred within $12-24 \mathrm{~h}$ of nucleation. Exceptions to this were observed, with three pits exhibiting bimodal growth kinetics and growing for 40 or more hours. This was explained by secondary droplets that formed near the pits, increasing the cathode area. A corrosion-driven drying mechanism likely contributed to pit death in both cases. Pits first grew into the material followed by lateral expansion.

npj Materials Degradation (2020)4:32; https://doi.org/10.1038/s41529-020-00136-3

\section{INTRODUCTION}

Predicting the kinetics and morphology of the localized damage produced during corrosion of passive alloys is a foundational challenge. This is especially the case for atmospheric corrosion, wherein the complex mechanistic interrelationships between environment, material microstructure and the electrochemical processes driving corrosion remain poorly understood. A major hurdle in assessing these relationships is the inability to directly measure and track local corrosion damage rates and morphology in-operando over extended periods without altering or interrupting the evolving process. Current procedures for studying atmospheric corrosion kinetics are destructive, e.g., mass loss, and provide little information on the evolution of individual pits in relation to the environment and microstructure. Alternatively, several studies in the past decade demonstrated that $\mathrm{X}$-ray tomography $(\mathrm{XCT})$ can be used to characterize corrosion-related damage non-destructively in-operando ${ }^{1-6}$. This study applies this tool to elucidate the long-term growth kinetics of atmospheric corrosion pits in aluminum.

Both laboratory-based and synchrotron XCT have been used to study pit growth under immersed and atmospheric conditions, for galvanic couples and the evolution of environmentally-assisted cracking ${ }^{2,4-15}$. Several recent studies utilized X-ray microtomography to directly measure the rate and morphology of intergranular corrosion of AA7075 and AA2024 during the initial stages of atmospheric corrosion under millimeter-sized chloride salt droplets $^{3,16,17}$. Du Plessis et al. ${ }^{17}$ observed the first $24 \mathrm{~h}$ of corrosion attack for $85 \% \mathrm{RH}$ under $\mathrm{NaCl}$ droplets for AA2024-T351. The first hours of attack occurred as fine intergranular fissures into the material that subsequently expanded laterally. Post-mortem characterization using XCT of AA2024 and AA7075 samples exposed for up to 7 days suggested a rapid increase in corroded volume after the first $\approx 3$ days of exposure ${ }^{18}$. This was explained as localized corrosion throughout the grain boundary network ${ }^{18}$.

Such studies provide unprecedented insight into the initial stages of pitting kinetics under millimeter-sized droplets, but the kinetics and morphological evolution over extended times remain unclear, particularly for pitting under the microscale droplets which are typical for many natural atmospheric environments ${ }^{19}$. Understanding how pits evolve under these conditions is critical to developing robust damage models for corrosive environments ${ }^{20}$. Laboratory studies of aluminum corrosion at longer times (weeks to months) have shown that volume loss and attack depth can reach a limiting value under a fixed amount of salt for high humidity conditions ${ }^{21-23}$. Schaller et al. found the time at which corrosion stifled strongly correlated with observed dry-up of electrolyte for $\mathrm{NaCl}$ droplets on $\mathrm{AA} 1100$ at $98 \% \mathrm{RH}^{23}$. This was attributed to corrosion stifling by a reaction of the cathode electrolyte with atmospheric $\mathrm{CO}_{2}$ during corrosion which precipitated sodium aluminum carbonate compounds that dry the surface ${ }^{23,24}$.

As a first step towards evaluating the relationship between pit growth, microstructure, and the evolving surface environment, this study applied XCT to characterize the evolving kinetics and morphology of pitting attack over 96 days of exposure for a $99.9 \%$ Al wire loaded with $60 \mu \mathrm{m} / \mathrm{cm}^{2}$ sodium chloride salt particles at $84 \% \mathrm{RH}$. This material and environment were chosen both for their pedagogical simplicity and for their relationship to previous work by the authors on aluminum atmospheric corrosion kinetics ${ }^{23}$. Focusing on this system provides insights into the effects of corrosion-induced electrolyte changes on atmospheric corrosion kinetics without the complicating factors of multiple phases or inclusion types typical in many engineering alloys. Specifically, this investigation examined the long-term growth kinetics of individual pits, factors that influenced this growth rate, and how pit morphology evolved over time.

\section{RESULTS}

In-situ XCT characterization

A brief summary of the experimental methods is provided here; detailed information is provided in the "Methods" section. The growth kinetics of atmospheric corrosion damage was characterized using in-situ XCT observations of a $1.02 \mathrm{~mm}$ diameter Al wire having a nominal purity of $99.9 \%$ Al, see Supplementary Fig. 1 for a schematic. Microscopy performed on samples of this material revealed Fe-rich strings of $\approx 1$ to $10 \mu \mathrm{m}$ inclusions aligned with the

\footnotetext{
${ }^{1}$ Sandia National Laboratories, P.O. Box 5800, Albuquerque, NM 87185-0889, USA. ${ }^{凶}$ email: pnoell@sandia.gov
} 
wire fiber direction (FD), Supplementary Fig. 2. EBSD data, see Supplementary Fig. 3, indicated that grains contained residual dislocation structures distributed as dislocation boundaries as is typically observed in deformed wavy glide materials such as $\mathrm{Al}^{25-30}$. More information on the material microstructure is provided in the Supplementary material.

The wire was cleaned and loaded with $\mathrm{NaCl}$ microparticles at a loading of $60 \mu \mathrm{g} / \mathrm{cm}^{2}$. The salt-loaded wire was then exposed to $84 \% \mathrm{RH}$ at $\sim 25^{\circ} \mathrm{C}$ for $2277 \mathrm{~h}$. A $2.5 \mathrm{~mm}$ length of the wire was imaged by XCT periodically over the course of the exposure using a $1.5 \mu \mathrm{m}$ voxel size, giving a spatial resolution of $27 \mu \mathrm{m}^{3}(2 \times 2 \times 2$ voxels). A total of 15 XCT datasets were collected. Because of the $3.5 \mathrm{~h}$ required to collect individual XCT datasets, the temporal uncertainty for all in-situ measurements is $\pm 1.75 \mathrm{~h}$. XCT datasets were collected at intervals of $7 \mathrm{~h}$ or less for the first $88 \mathrm{~h}$ of exposure. XCT scans of the sample were also begun after 1116 and $2270 \mathrm{~h}$ of exposure.

Within the $27 \mu \mathrm{m}^{3}$ spatial resolution of XCT data, nine discrete pits nucleated within the first $88 \mathrm{~h}$ of exposure. Eight more pits formed between 88 and $2270 \mathrm{~h}$ of exposure, but the evolution of these pits was not captured by the scan schedule used for this study. Excepting Fig. 1, the eight pits that nucleated after $88 \mathrm{~h}$ of exposure are not hereafter discussed. Based on XCT measurements, cumulative volume loss over the area characterized with XCT is plotted as a function of time in Fig. 1a. The total number of pits observed at each time step per unit area of wire inspected are plotted in Fig. $1 \mathrm{~b}$.

Plots of pit volume as a function of time for the nine pits observed during the first $88 \mathrm{~h}$ of exposure are shown in Fig. 2 . The final volumes of all nine pits are provided in Table 1. Note that the growth kinetics and morphology of the three pits not included in Fig. 2, pits 7-9, were similar to that of the three pits shown in Fig. 2a, pits 1-3.

As this figure shows, pits can be separated into two general categories:

- small pits: six of the nine pits ceased observable growth less than $25 \mathrm{~h}$ after nucleation and had final volumes less than $4000 \mu^{3}$ and

- large pits: three of the nine pits grew for 46 or more hours and reached final volumes greater than $13,000 \mathrm{\mu m}^{3}$.
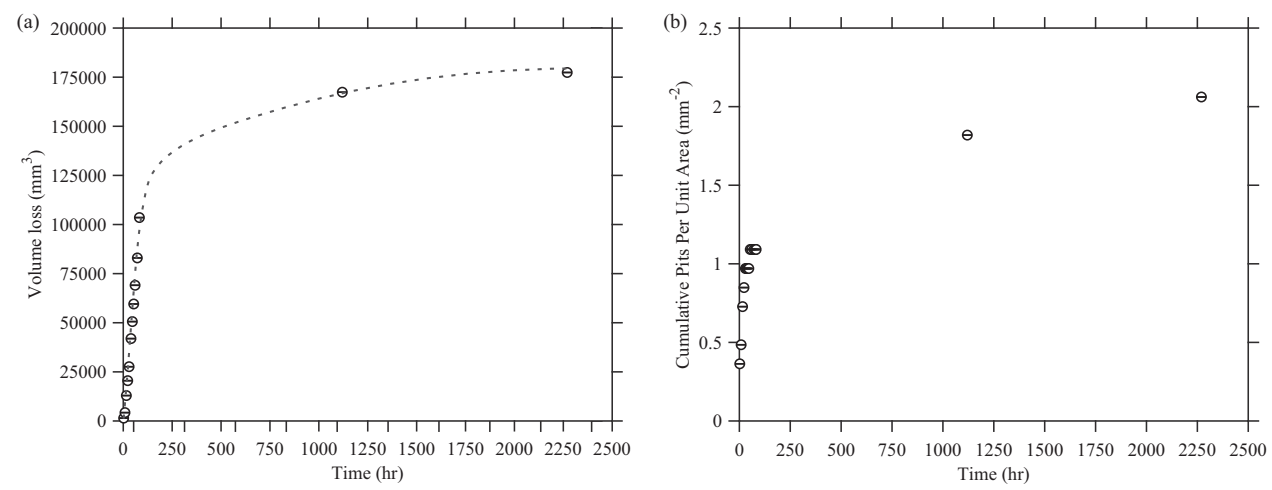

Fig. 1 Overall volume loss and nucleation rate kinetics. Cumulative volume loss (a) and cumulative pits per unit area observed at each time step (b) are plotted as functions of time. Trend lines are added to aid data visualization.
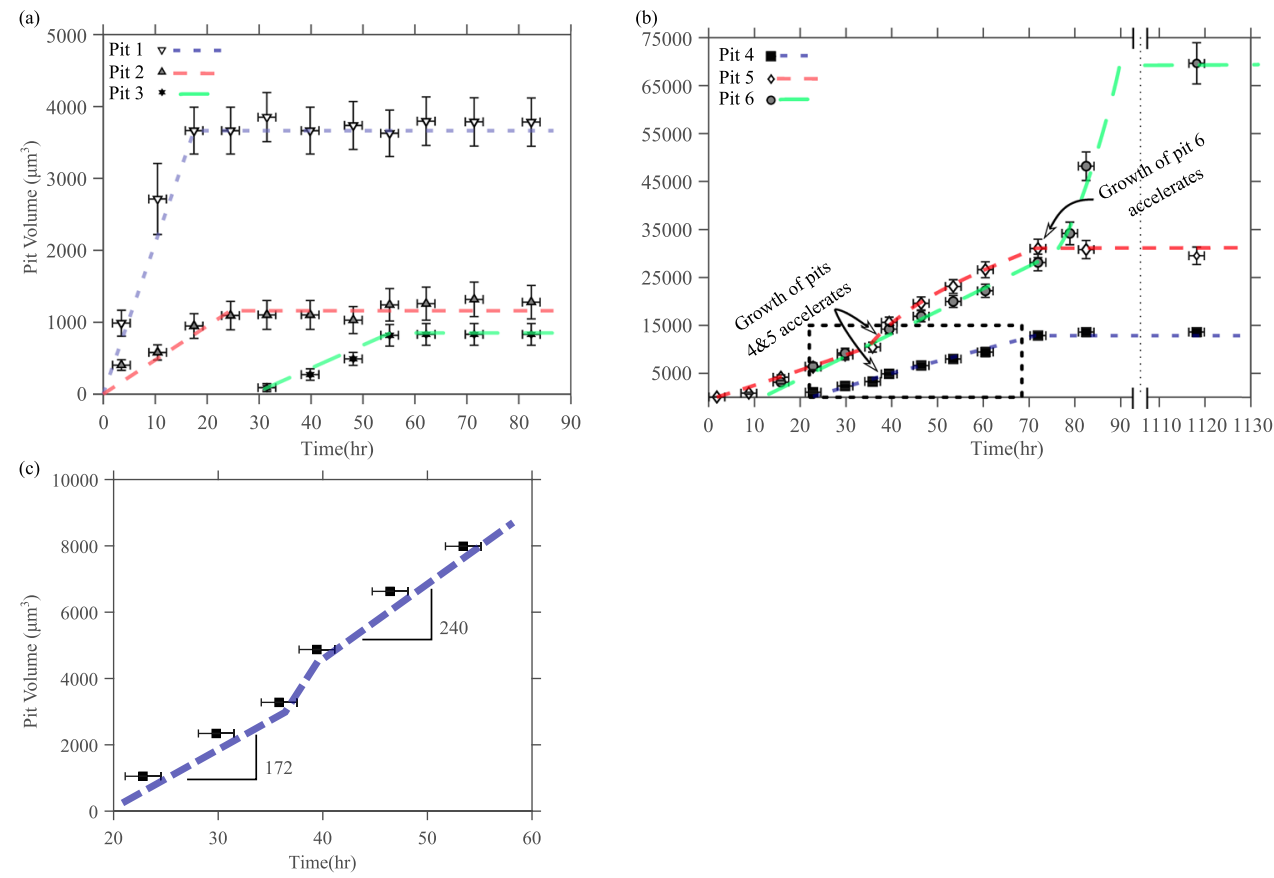

Fig. 2 Growth kinetics of individual pits. Plots of pit volume as a function of exposure time are provided for six pits in (a) and (b). Note the split in the $\mathrm{x}$-axis between $90 \mathrm{~h}$ and $1110 \mathrm{~h}$ for (b). c Highlights a change in growth rate for pit 4, see boxed area in (b). Error bars represent measurement uncertainty in volume and time as described in the "Methods". 
Table 1. Growth kinetics of individual pits.

\begin{tabular}{lllllllll}
\hline & Pit 1 & Pit 2 & Pit 3 & Pit 4 & Pit 5 & Pit 6 & Pit 7 & Pit 8 \\
\hline Final volume $\left(\mu \mathrm{m}^{3}\right)$ & 3800 & 1300 & 800 & 13600 & 30900 & 69700 & 800 & 1440 \\
Initial growth rate $\left(\mu \mathrm{m}^{3} / \mathrm{h}\right)$ & 194 & 39 & 30 & 172 & 370 & 439 & 32 & 65 \\
Secondary growth rate $\left(\mu \mathrm{m}^{3} / \mathrm{h}\right)$ & - & - & - & 240 & 475 & 3930 & - & - \\
Time growing $(\mathrm{h})$ & 12 & 19 & 24 & 46 & 72 & $>65$ & 14 & 14 \\
Maximum depth $(\mu \mathrm{m})$ & 26 & 13 & 12 & 30 & 22 & 44 & 14 & 16 \\
\hline
\end{tabular}

The final volume initial and secondary pit growth rates the length of time during which the pit grew and the maximum depth to which the pit grew are shown for 9 pits that nucleated within the first $88 \mathrm{~h}$ of exposure.
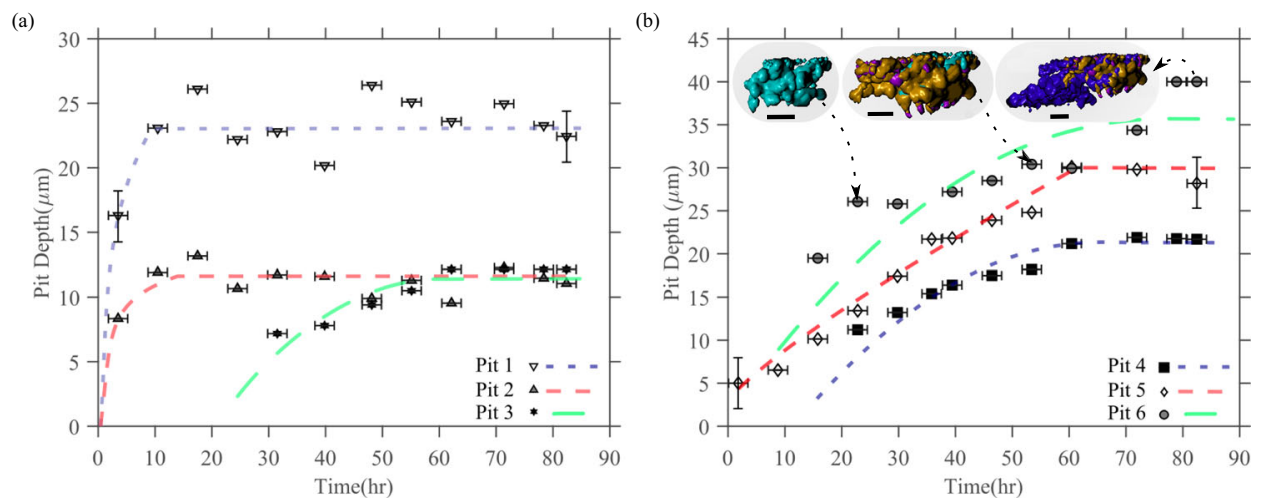

Fig. 3 Pit depth as a function of time. Plots of pit depth as a function of exposure time are provided for six pits in (a) and (b). No change in the maximum depth of any of the pits was observed after $81 \mathrm{~h}$ of exposure, including Pit 6 . All depth measurements are $\pm 3.0 \mu \mathrm{m}$, see the first and last datapoints plotted for Pits 1 and 5. 3D renderings of pit 6 at three different time steps are shown; images are at different scales. The scale bar for the insets in (b) is $15 \mu \mathrm{m}$. Error bars represent measurement uncertainty in depth and time as described in the "Methods".

Excepting pit 6, no measurable volume change was observed in any of these pits after $71 \mathrm{~h}$ of exposure. The time elapsed between observable pit formation and growth cessation for each pit except pit 6 is summarized in Table 1. Pit 6 continued to grow after the $\mathrm{XCT}$ scan that ended after $88 \mathrm{~h}$ of exposure. The volume of this pit did not change measurably between scans after $1116 \mathrm{~h}$ and $2270 \mathrm{~h}$ of exposure, indicating that growth of this pit ceased between 88 and $1116 \mathrm{~h}$ of exposure. At least $65 \mathrm{~h}$ elapsed between when this pit formed and when it ceased growing.

Figure $2 a$ indicates that the growth rate of all small pits was approximately linear. Linear regression $\left(r^{2} \geq 0.96\right)$ was used to measure the growth rates of small pits, as summarized in Table 1. Figure $2 \mathrm{~b}$ indicates that the growth rate of all large pits was also initially linear. Measurements of the initial growth rates of these pits using linear regression $\left(r^{2} \geq 0.98\right)$ are provided in Table 1 . As the arrows on Fig. $2 \mathrm{~b}$ highlight, after an initial period of linear growth, the growth rate of each of the large pits accelerated nonlinearly until it reached a new, faster, growth rate. This occurred at the same timestep for pits 4 and 5 . For pits 4 and 5 , linear regression $\left(r^{2} \geq 0.99\right)$ measurements of this secondary growth rate are listed in Table 1 . Using the two datapoints available, the secondary growth rate of pit 6 was measured to be $3930 \mu \mathrm{m}^{3} / \mathrm{h}$.

XCT data were used to measure the maximum depth of each pit at each time step. These data are plotted as a function of time for pits 1-6 in Fig. 3. Parabolic fits for the data for pits 3, 4, 5, and 6 are overlaid; the pit depth data for pits 1 and 2 were insufficient for parabolic fits. The final maximum depth of all nine pits are summarized in Table 1. To better aid in understanding how pit shape evolved over time, pit depth as a function of pit volume is plotted in Supplementary Fig. 4 for the three largest pits.
Plots of final pit volume and initial pit growth rate as a function of initial electrolyte volume are provided in Fig. 4. Because three pits nucleated before the first XCT dataset was collected, only the electrolyte volume after the pit nucleated could be measured. For the other six pits, the volume of the droplets associated with the pits in the time steps immediately before and after pit nucleation was averaged and is plotted in Fig. 4.

The coverage area of the droplets associated with all pits are provided as a function of time in Fig. 5. Note that corrosion products and the electrolyte phase could not be clearly distinguished in XCT data. Hence, after significant pit growth occurred, it is likely that coverage area measurements include contributions from both.

Time-lapse horizontal slices through X-ray tomograms of one of the three large pits, pit 4, are shown in Fig. 6. The upper row shows a top-down view of the evolving droplet and corrosion product. The arrows in the image of droplets after $15 \mathrm{~h}$ of exposure highlight the droplet under which the pit nucleated (white arrow) and a nearby droplet (gray arrow). Arrows at subsequent timesteps highlight droplet spreading or, for the image at $46 \mathrm{~h}$, droplet drying. The three lower rows show views of the pit. Arrows in these images highlight approximately the same location as those indicated in the upper row of images. Timelapse, 3D renderings of pit 4, and the associated droplet and corrosion product are shown in Fig. 7. As in Fig. 6, the arrows highlight droplet spreading associated with this pit.

The pit growth and droplet spreading shown for pit 4 in Figs. 6 and 7 (2D and $3 D$ renderings, respectively) were typical of the three large pits. For comparison, time-lapse horizontal slices through x-ray tomograms of a typical small pit, pit 3 , are shown in Fig. 8. This pit nucleated between $22 \mathrm{~h}$ and $29 \mathrm{~h}$ and ceased 


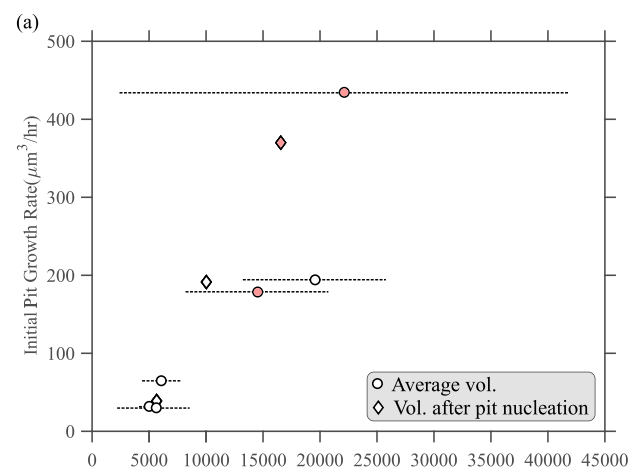

Initial Droplet Volume $\left(\mu \mathrm{m}^{3}\right)$

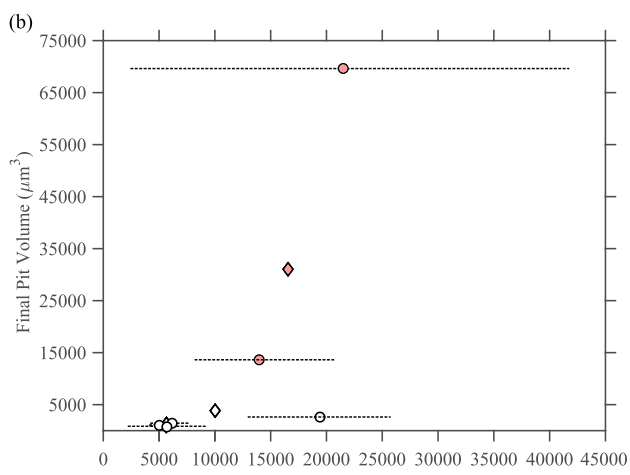

Initial Droplet Volume $\left(\mu \mathrm{m}^{3}\right)$

Fig. 4 Relationship between droplet size and pit growth. Initial pit growth rate (a) and final pit volume (b) are plotted as functions of initial droplet volume. Diamonds mark the three pits for which only droplet size after pit nucleation was measured. Circles show the average droplet volume associated with the other pits. The line spans the range between the size of the droplet before and after pit nucleation for these pits. Data associated with large pits are colored orange. Data associated with small pits is colored white.
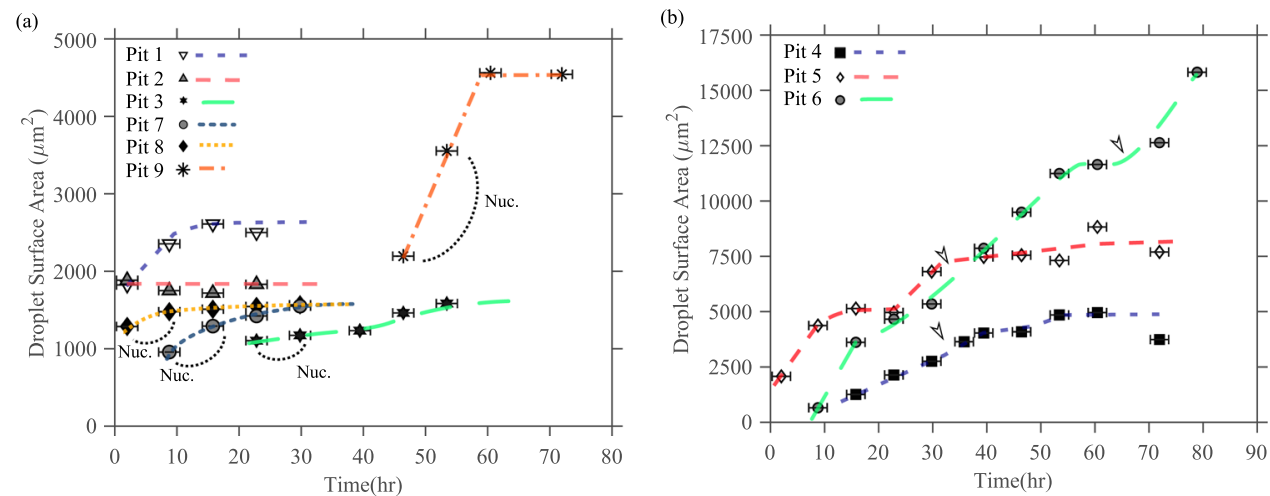

Fig. 5 Evolving droplet coverage area. Droplet coverage area associated with each pit is provided as a function of time in (a) and (b). For all pits except pit 6, no change in droplet coverage area was observed after the final datapoint provided for that pit. Arrows indicate time steps associated with the acceleration of pit growth for pits 4, 5, and 6 . The time steps between which pits nucleated are also indicated. Note that pits 1, 2, and 5 nucleated before the first scan was completed. Error bars represent measurement uncertainty in time as described in the "Methods".

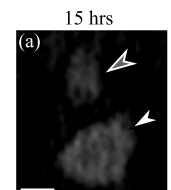

(b)

(c)

(d)
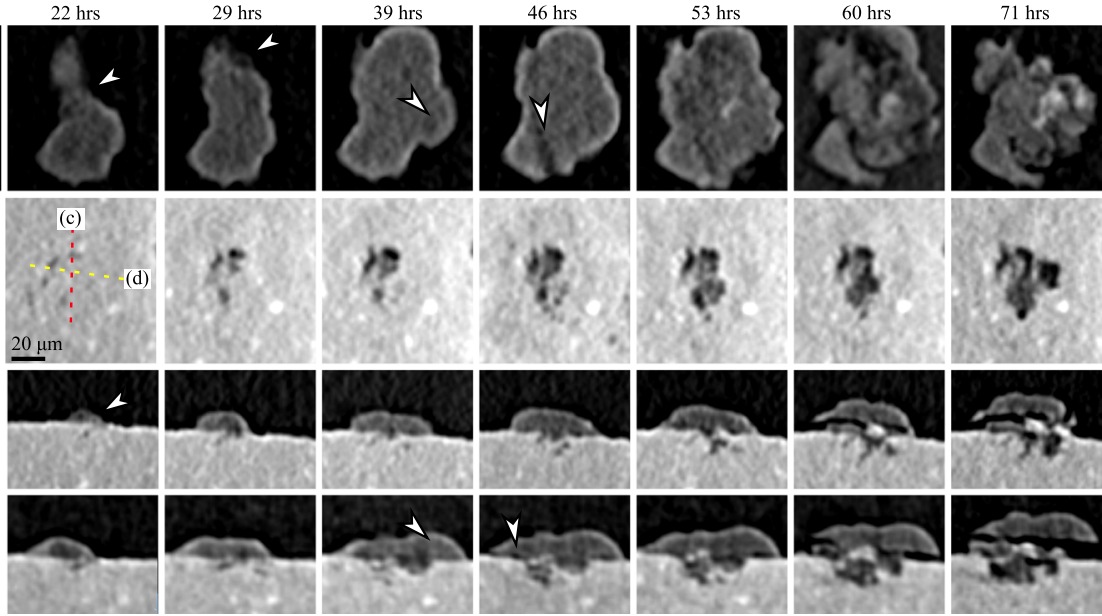

Fig. 6 Two-dimensional views of a growing pit. Horizontal tomograms showing the evolution of Pit 4 are shown. a Shows top-down views of the evolution of the droplet and corrosion product associated with this pit between $15 \mathrm{~h}$ (before pit nucleation) and $71 \mathrm{~h}$. $\mathbf{b}$ Shows a top-down view of the corrosion damage associated with this pit. c, d Show horizontal sections along the planes shown in (b). The scale bar in (a, b) is $20 \mu \mathrm{m}$ and all images are at the same scale. Arrows in (a) at $15 \mathrm{~h}$ of exposure highlight the two droplets associated with this pit. The pit nucleated beneath the larger of the two droplets. All other arrows highlight changes in the droplet and corrosion product. 


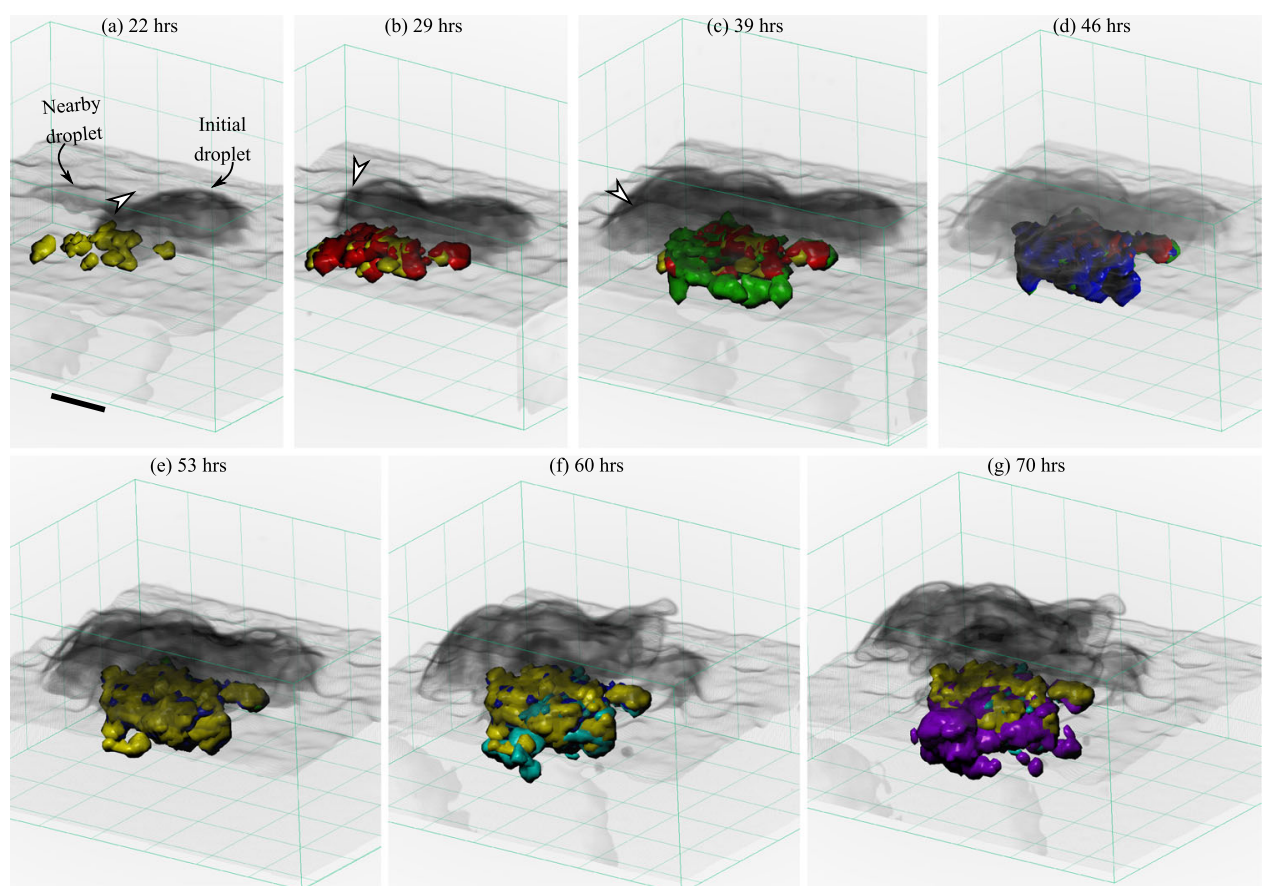

Fig. 7 Three-dimensional renderings of a growing pit. 3D renderings of Pit 4 and the evolving droplet and corrosion product are shown at the indicated time intervals in (a) to $(\mathbf{g})$. Each color change of the pit reveals additional growth of the pit relative to the two previous time intervals. The initial droplet under which this pit nucleated and a nearby droplet are labeled in (a). The arrows in (a-c) correspond to the same locations shown in Fig. 6 at each time step. The scale bar in (a) and the grid size around each rendering is $20 \mu \mathrm{m}$.

growing between 46 and $53 \mathrm{~h}$ after exposure began. Before this pit nucleated, two discrete droplets (see Fig. 8(a), 15 h.) merged (see Fig. 8(a), $22 \mathrm{~h}$.). XCT data suggest that this pit nucleated beneath the tertiary droplet that joined these two droplets.

\section{Post-mortem characterization}

Results of Fourier-transform infrared spectroscopy (FTIR) performed on the corrosion product formed at pit 4 are provided in Supplementary Fig. 5. These data indicated the presence of Dawsonite $\left(\mathrm{NaAlCO}_{3}(\mathrm{OH})_{2}\right)$ in the corrosion product. Other corrosion product compounds were not detected or could not be definitively resolved. Similar results were observed at 5 other pits.

To characterize the relationship between pit morphology and the underlying microstructure, focused ion beam (FIB) was used to cross-section pit 4 . A representative secondary electron image of this pit is provided in Fig. 9a. The location of this cross-section shows a similar slice of this pit to that shown in Fig. $6 \mathrm{c}$ at $71 \mathrm{~h}$. Comparing these images reveals that XCT did not resolve the rough morphology around the edges of these pits, particularly near the bottom of the pit.

Electron backscatter diffraction (EBSD) analysis of the FIB crosssectioned area shown in Fig. 9b further indicates that attack propagated along dislocation and grain boundaries. Grain and dislocation boundary attack appeared to have been non-selective with respect to the misorientation angle, as exemplified by the five labeled grain boundaries in Fig. $9 c$ that were partially corroded. The influence of inclusions, including the iron-rich particles seen in Figures (a) and (b), on the propagation pathway was not clear from cross-sectional analysis. Energy-dispersive X-ray spectroscopy (EDS) data, provided in Supplementary Fig. 6, indicated that the pit was largely Al poor and O-rich, indicating that it was almost entirely filled by aluminum corrosion products, Dawsonite/Al-oxide/hydroxide. EDS data indicated that the center of the corrosion product was $\mathrm{Cl}$ rich and $\mathrm{Na}$ deficient. The opposite was observed near the edges of the droplet/corrosion product.

\section{DISCUSSION}

In-operando XCT provides an unprecedented window into how individual corrosion events contribute to the overall mass-loss behavior measured using conventional techniques. The trend in cumulative volume loss observed in Fig. 1 is consistent with previous studies of Al under fixed salt load and constant humidity conditions: after some period of initial corrosion upon humidity exposure 22,23 , measurable loss effectively ceases. This occurred after similar exposure times $(100-500 \mathrm{~h})$ in both this study and in those of refs. ${ }^{22,23}$. In-operando XCT data show that this trend is reflective of two primary factors. First, stable pit initiation occurs at a relatively fast rate at the start of humidity exposure. The appearance of new stable pits decreases to a negligible rate after the first 3 days of exposure. Second, all growing pits individually ceased growing, typically within $12-50 \mathrm{~h}$ of nucleation. XCT data thus indicate that the trend observed in Fig. 1 is primarily related to the pit-nucleation rate slowing over time.

While the growth kinetics of individual pits show some similarities with the trend of cumulative mass loss, they exhibited up to three stages of growth that are not apparent in cumulative volume loss data: (1) initial growth showing linear behavior, (2) a non-linear increase in volume loss followed by a second linear growth regime, only observed for three of the nine pits, and (3) the cessation of pit growth within the resolution of the XCT. Because the limited temporal resolution of XCT in this study impeded characterization of pit nucleation and the transition from pit growth to stifling, these stages will not be discussed in detail. Note that no correlation between the growth rate and the presence, size, and/or number of Fe-rich inclusions under droplets could be observed, which may in part be due to the resolution limits of our method. Al-Fe inclusions, specifically $\mathrm{Al}_{3} \mathrm{Fe}$ 


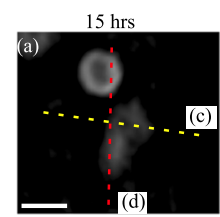

(b)
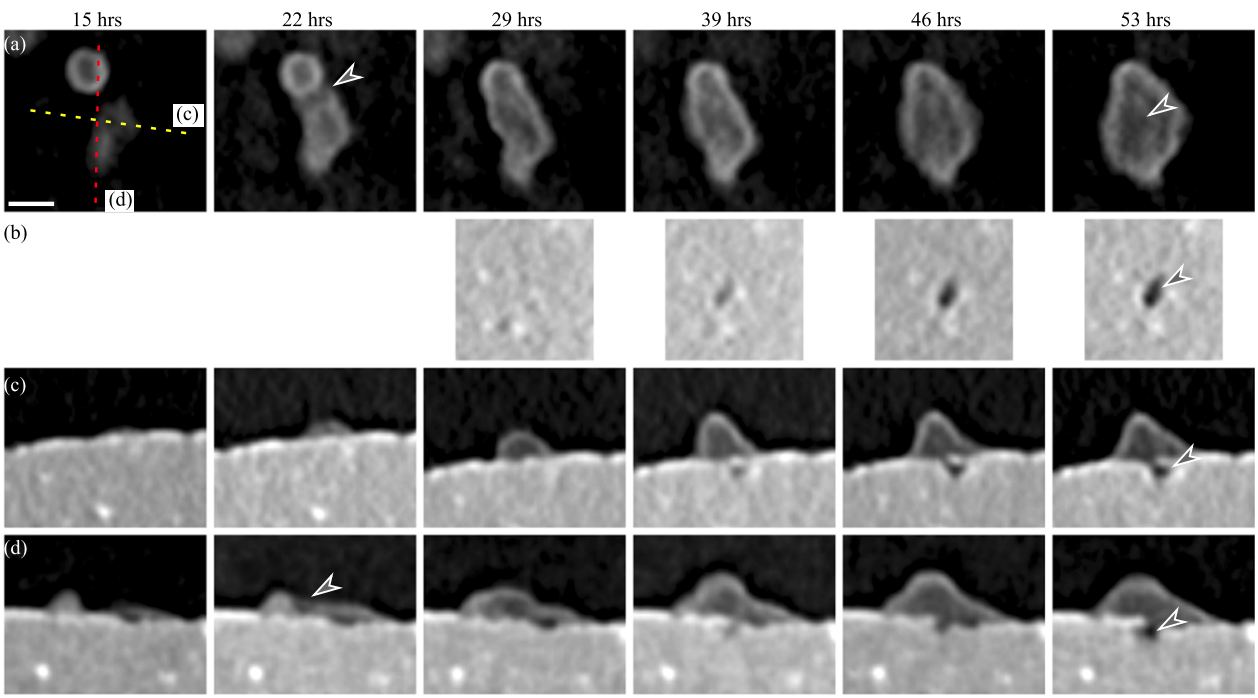

Fig. 8 Two-dimensional views of a growing pit. Time-lapse tomograms showing the evolution of Pit 3 are shown. a Shows top-down views of the droplet and corrosion product associated with this pit between $15 \mathrm{~h}$ (before pit nucleation) and $53 \mathrm{~h}$. $\mathbf{b}$ Shows a top-down view of the corrosion damage associated with this pit beginning at $29 \mathrm{~h}$, the first timestep when a pit was observed at this location. c, d Show horizontal sections along the planes shown in (b). The pit nucleated below the intersection of these two lines. The scale bar in (a) is $20 \mu \mathrm{m}$ and all images are at the same scale. Arrows in (a) at $22 \mathrm{~h}$ of exposure highlight the spreading of an initial drop to a nearby drop. The arrows at $53 \mathrm{~h}$ of exposure indicate approximately the same location.
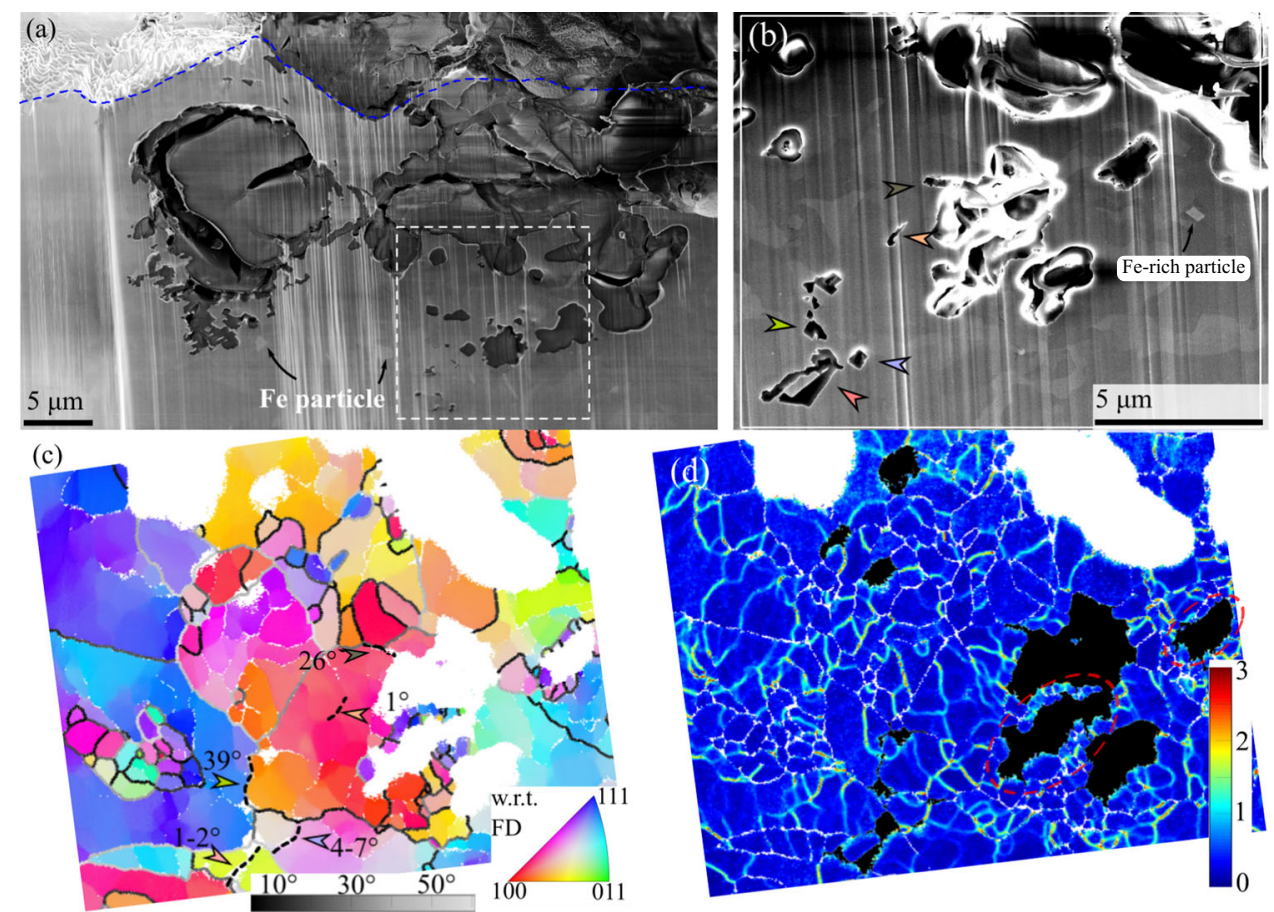

Fig. 9 Post-mortem microscopy of a pit. Secondary electron images and EBSD maps from a FIB cross-section of Pit 4 are shown. a Shows a secondary electron image of the cross-section and the dashed curve approximately indicates the original wire surface. $\mathbf{b}$ Shows a detail-image of the boxed area in (a). Inverse pole figure (IPF) and kernel average misorientation (KAM) maps in (c, d) are from a location within proximity of (b) with color-coded arrows highlighting the same locations across select corroded boundaries. The IPF map is colored with respect to the fiber direction with the grain boundaries colored according to the misorientation angle (gray scale). Unindexed pixels in (c, d) are white excepting corrosion damage that is surrounded by undamaged material within the area inspected in (d). This is colored black. The scale bars in $(\mathbf{a}, \mathbf{b})$ are $5 \mu \mathrm{m}$. Data in $(\mathbf{c}, \mathbf{d})$ are at the same scale as those shown in (b).

intermetallics, are known to serve as local preferential cathodes that can act as pit initiation sites in Al alloys ${ }^{31,32}$.

There are two key features of linear pit growth: the volume-loss over time for each pit was approximately linear and the rate of volume loss varied by more than an order of magnitude between the nine pits, see Table 1 and Fig. 2. Linear volume loss implies that the average cathodic current supplied to individual pits was constant. Pit growth during atmospheric corrosion of aluminum in neutral chloride electrolytes is thought to be cathodically controlled and predominately driven by oxygen reduction ${ }^{16,33}$. Given this, it is 
likely that pit-growth kinetics during this stage were primarily controlled by the size and efficiency of the cathode. While these quantities can evolve for Al during atmospheric exposure (see next paragraphs), the initial corrosion rate was likely related to the initial cathode size. Such a relationship was observed, see Fig. 3, with increasing corrosion rates associated with increasingly large droplets. Higher temporal resolution than that used in this study and further observations of the relationship between droplet size and pit growth kinetics will be necessary to develop a clear relationship between initial cathode size and pit growth rate. Furthermore, why growth rates can remain nominally constant for up to $\approx 56 \mathrm{~h}$ despite evolving conditions remains an area for future study.

For three of the nine pits observed, after a period of constant growth ranging from 13 to $56 \mathrm{~h}$, pit growth accelerated nonlinearly before stabilizing at a new and faster linear rate, see Fig. 2b. The point of acceleration correlated to the appearance of secondary droplets, as discussed subsequently. We hypothesize these secondary droplets served to increase the available cathodic area which in turn drove faster growth.

The droplet coverage area associated with all pits increased during the initial growth stage until it reached a plateau, generally within $12-24 \mathrm{~h}$ of pit nucleation, see Fig. 5. For small pits, this plateau was associated with pit growth stagnation, discussed in the next paragraph. As Figs. 6 and 8 show, increases in droplet coverage area during initial linear growth were associated either with droplet spreading to connect neighboring droplets, such as that which occurred for pit 4 between 15 and $22 \mathrm{~h}$ of exposure, or expansion of the droplet slightly in all directions, such as occurred for pit 3 between 29 and $53 \mathrm{~h}$ of exposure. The latter observation may be attributable to corrosion product formation increasing the apparent droplet size rather than droplet spreading.

Consider now the evolution in droplet coverage area associated with pits 4 and 5 between 22 and $39 \mathrm{~h}$ and that associated with pit 6 between 60 and $80 \mathrm{~h}$. The droplet coverage area associated with each of these remained at a plateau for $\approx 7 \mathrm{~h}$ then increased. The increased droplet coverage area was created by the formation of secondary droplets at the edge of the primary droplet. Significant pit growth occurred beneath these secondary drops, see Figs. 6 and 7 , accelerating the overall growth of this pit.

Secondary droplets and thin electrolyte films are commonly observed to form around sodium chloride drops on corroding aluminum and other alloys in humid conditions ${ }^{17,33-36}$. These secondary electrolytes can be resultant from oxygen reduction activity near the periphery of the original salt drop (cathodic spreading) or metal dissolution associated with pitting near the periphery (anodic spreading). Both have been observed for $\mathrm{NaCl}$ drops on aluminum alloys ${ }^{17,33}$ and both can increase the available cathode area, increasing the total cathodic current capacity. Du Plessis ${ }^{17}$ observed that microdroplets attributed to cathodic spreading formed shortly after exposure began and that the secondary spreading region continued to grow throughout the first week of exposure for AA2024 under NaCl drops. Severe localized attack was found in the spreading region around the drop periphery, suggesting that it can support both anodic and cathodic processes. In the case of anodic spreading, Morton et al. found that secondary droplets formed around pits near the edge of $\mathrm{NaCl}$ drops on $A A 7075^{33}$. This led to the primary droplet serving as the cathode supporting intense anodic dissolution in the secondary droplet, similar to what was observed in the current study.

Within the $27 \mu \mathrm{m}^{3}$ resolution of these XCT data, the growth of all pits eventually and abruptly ceased. This indicates that the current demand for pit growth exceeded the available cathode supply and/ or corrosion product precipitation and electrolyte dry-up inhibited both anodic and cathodic kinetics ${ }^{23,37}$. Regarding the latter, Schaller et al. showed that, under similar conditions, sodium chloride drops on aluminum can dry-up during corrosion due to the precipitation of Dawsonite ${ }^{23,37}$. This drying behavior strongly correlated to pitting stagnation. The presence of Dawsonite in the corrosion product after exposure indicates that this corrosion-driven drying mechanism likely played a role.

It is expected that pit geometry and/or the trajectory of pit growth may change in the last hours of pit growth as cathodic and anodic reactions become increasingly limited. For example, the selective attack observed at the base of this pit, see Fig. 9, may be characteristic of the last hours of pit growth rather than the faceted morphology near the surface. Future XCT experiments with higher time and spatial resolution than that used in this study may help elucidate the transition from stable pit growth to pit death.

Assuming similar pit shapes, according to both cathode-supply limitation and corrosion-driving drying, increasingly larger initial droplets should be able to sustain larger pits, a trend generally seen in Fig. 3. Exceptions to this trend may be explained by the increased cathode size created by droplet spreading, which impeded pit-growth stagnation. Pits that did not form secondary droplets stagnated within, at most, $24 \mathrm{~h}$ of pit nucleation while repassivation of pits that formed secondary droplets occurred more than $45 \mathrm{~h}$ after such pits nucleated. Incorporating droplet spreading and dry-up into cathodically governed pit growth models may thus lead to improved predictions in final pit size ${ }^{37,38}$.

The irregular pit shapes along with volume loss trends indicate that pits grew under severe cathodic limitation, likely near conditions on the edge of passivity ${ }^{39-41}$. In this study, the attack appeared to propagate along grain and dislocation boundaries. Similar selective attack associated with grain boundaries has been observed in particle-free $\mathrm{Al}^{42}$. It is generally assumed that highangle grain boundaries are more susceptible to localized corrosion attack than low angle grain boundaries ${ }^{43,44}$. However, both high and low-angle grain boundaries and dislocation boundaries showed signs of preferential attack, see Fig. 9.

Understanding how morphology evolves during pitting is critical to accurately predicting the stress concentration associated with pits. Damage models typically assume that pits are hemispherical or semi-elliptical ${ }^{45-48}$. However, in-situ measurements of pit morphology in this study demonstrated that pits were irregular and first grew into the material until reaching a maximum depth and subsequently expanded laterally. This is consistent with previous work by our group under similar conditions and may be reflective of IR drop effects impeding further growth into the surface ${ }^{23}$. Similar behavior was also observed during intergranular corrosion of AA2024 under mmsized $\mathrm{NaCl}$ drops using $\mathrm{XCT}^{3,16-18}$. Given the significant evolution in pit morphology during growth, it is possible that the largest stress concentration created by these pits occurred before growth ceased. Assessing stress concentration from post-mortem measurements would then be non-conservative.

In conclusion, the XCT data presented in this study demonstrated that the growth kinetics of individual pits are significantly different from the kinetics of overall volume-loss. Cumulative volume-loss exhibited logarithmic kinetics, with the rate of volume loss decreasing significantly over time. XCT data from individual pits showed that this trend was related to the rate of pit nucleation, which slowed significantly after the first 3 days of exposure, rather than the growth kinetics of individual pits. Most pits exhibited a linear and roughly constant rate of volume-loss up until pit death, which occurred within 12-24h of nucleation. Exceptions to this were observed, with three pits exhibiting bimodal growth kinetics and growing for 40 or more hours. These exceptions were explained by droplet spreading, which appears to accelerate pit growth and impede pit death by creating a larger cathode area. For both cases, a corrosion-driven drying mechanism appears to contribute to pit death. These data indicate that mechanistic atmospheric pit-growth models for $\mathrm{Al}$ and other engineering alloys may be improved by considering the effects of both droplet spreading and cathode drying.

This study also demonstrated the utility of laboratory-based XCT to directly observe corrosion damage in-operando over an 
extended period. Synchrotron-based tomography techniques provide spatial and temporal resolutions as low as $0.1 \mu \mathrm{m}$ and minutes, significantly superior to the $3 \mu \mathrm{m}$ and $7 \mathrm{~h}$ spatial and temporal resolutions used in this study; however, time constraints limit the applicability of synchrotron-based techniques to atmospheric corrosion, where damage evolves over extended periods (days or weeks). The method used in this study is thus complimentary to synchrotron-based techniques in that it enables regular inspection of samples over extended periods. If needed, the spatial and temporal resolution of laboratory-based XCT techniques can be increased to $\approx 1-2 \mu \mathrm{m}$ and $\approx 1 \mathrm{~h}$, though at a cost of characterizing a smaller area. By providing information about the evolving pit and droplet in three-dimensions, it also provides data that will complement that from other characterization techniques, such scanning Kelvin probe or optical microscopy.

\section{METHODS}

\section{Material}

The Al wire material used in this study was acquired from ESPI metals (Ashland, Oregon). Independent compositional analysis of this material was conducted using inductively coupled plasma mass spectroscopy ${ }^{49}$. The composition of this material (in ppm) was measured to be Mg 14, V 3 , Cu 6, Zn 30, Ti 182, Ga 246, Fe 416, and Si 146, with the remainder being Al. Energy-dispersive X-ray spectroscopy (EDS) analysis, described in a subsequent paragraph, revealed that this material contained distributed iron-rich particles, likely $\mathrm{Al}_{3} \mathrm{Fe}$ particles, which are common in commercialpurity Al materials ${ }^{31}$. The principal axes of this material are defined as the fiber direction (FD), i.e., parallel to the length of the wire, and the radial direction RAD, i.e., parallel to the wire diameter.

\section{Microscopy}

To characterize the as-received microstructure of this material, specimens were cut from the wire, mounted in epoxy, ground, and polished using a final polish of $0.05 \mu \mathrm{m}$ colloidal silica for extended periods. To characterize the three-dimensional grain structure, specimens were prepared for observation of both the planes parallel to the FD and RAD. Polished specimens were subsequently examined using a Zeiss Supra 55VP field emission scanning electron microscope (SEM). EDS was performed with an Oxford Instruments X-Max SDD EDS to analyze the particles observed within the microstructure. To characterize the grain structure in the $\mathrm{Al}$ material, electron backscatter diffraction (EBSD) data were also collected using Oxford HKL Aztec ${ }^{\mathrm{TM}}$ software. All EBSD data collected in this study were processed using $M_{T E X^{50}}$, an extension for MATLAB. Grains were defined in MTEX by assigning neighboring points misoriented by less than $5^{\circ}$ to the same grain and enforcing a minimum grain size of 10 adjacent points. Using MTEX, EBSD data were also used to qualitatively evaluate the dislocation structure in the Al material. Many metrics have been proposed for assessing residual dislocation structure using EBSD data, see reference ${ }^{51}$ for more information. The metric used in this study was kernel average misorientation (KAM). KAM was calculated using the misorientation between each pixel in a grain and its two nearest neighbors, excluding nearest neighbors that were part of a different grain.

\section{XCT characterization}

To prepare a specimen for in-situ characterization of atmospheric corrosion damage, a $25 \mathrm{~mm}$ long sample was cut from the Al material and cleaned as follows: $1.5 \mathrm{~min}$ in $1.0 \mathrm{M} \mathrm{NaOH}$ at $60^{\circ} \mathrm{C}$, deionized water rinse, $0.5 \mathrm{~min}$ in $70 \% \mathrm{HNO}_{3}$, deionized water rinse, compressed air dry. The wire was then attached to a plastic holder. Near saturated sodium chloride solution was printed along the length and around the circumference of the wire at an ambient $\mathrm{RH}$ of $80 \%$ and temperature of $21^{\circ} \mathrm{C}$ onto the wire using a LogoJET ProH4 industrial inkjet printer (LogoJET USA) following a procedure similar to that of Schindelholz and Kelly ${ }^{52}$. Printing produced uniform fields of discrete picoliter-sized droplets with a salt loading of $60 \mu \mathrm{g} / \mathrm{cm}^{2}$ around the entire circumference of the wire.

The entire wire was subsequently encapsulated in a plastic tube that contained a sponge, as shown in Supplementary Fig. 1. The bottom of the tube was sealed, and the experimental setup subsequently attached to an Al post for easy insertion and removal from the XCT system (described in a subsequent paragraph). Immediately before beginning XCT characterization, a few droplets of a super-saturated $\mathrm{KCl}$ were added to the sponge to create an $84 \% \mathrm{RH}$ atmosphere within the tube ${ }^{53}$. The top of the tube was sealed with a plastic cap and the assembly was placed within the XCT system. When the assembly was not being analyzed in the XCT system it was stored in a sealed jar that was maintained at $84 \% \mathrm{RH}$ to ensure that any leaks in the assembly did not result in the sample drying. The sample remained at room-temperature $\left(\approx 25^{\circ} \mathrm{C}\right)$ throughout exposure.

In-situ characterization was performed using a lab-based XCT system (Zeiss Xradia Versa 520, Carl Zeiss XRM, Pleasanton, CA). Each scan was performed using an accelerating voltage of $50 \mathrm{kV}$ and a power of $4 \mathrm{~kW}$. No beam filter was used. The XCT scans were performed using a voxel size of $1.5 \mu \mathrm{m}$. The same $2.5 \mathrm{~mm}$ portion of the wire was characterized throughout the experiment. This section of the wire was approximately equidistant from the top and bottom of the wire. To observe this length of the wire, two XCT datasets were stitched together. For each dataset, a total of 1601 projections (radiographs) over $360^{\circ}$ was taken with an exposure time of $6 \mathrm{~s}$ for each projection. 5 reference (full beam without sample) scans, each consisting of 10 separate exposures, at an interval of 350 projections were taken during collection of each dataset for background subtraction and normalization of the tomographs. The data collection time for an individual XCT dataset was $\sim 3.5 \mathrm{~h}$; the total collection time for each stitched XCT dataset was $\sim 7 \mathrm{~h}$. Save for the exceptions described in the next paragraph, the volume of an individual feature was thus assessed approximately every $7 \mathrm{~h}$ with a temporal uncertainty at each timestep of $\pm 1.75 \mathrm{~h}$. The radiographs from each scan were automatically reconstructed using the Zeiss XMReconstructor software, which uses a standard filtered back-projection algorithm.

A total of 15 XCT datasets were collected over $2273 \mathrm{~h}$ (94.5 days) with all but two of these scans being collected in the first $88 \mathrm{~h}$ of exposure. Following an initial 1-hour warmup scan to stabilize the beam, subsequent scans started 1, 8.0, 15.0, 22.0, 29.0, 35.0, 38.6, 45.6, 52.6, 59.6, 71.1, 78.1, $81.7,1115.7$, and $2269.8 \mathrm{~h}$ after exposure began, respectively. The labeled time elapsed after exposure for each XCT dataset is this time step rounded to the nearest hour. Note that, for the two scans that began after 34 and $77.1 \mathrm{~h}$ after exposure, the source failed to stabilize before the second scan was collected. Only the first of the two stitched datasets were collected for these two timesteps. When this occurred, the software automatically began collecting the next dataset. Thus, in two instances, the same $\sim 1.5 \mathrm{~mm}$ tall volume of the wire was characterized at an interval of approximately $3.5 \mathrm{~h}$. This area contained six of the nine pits which nucleated in the first $88 \mathrm{~h}$, pits 4-9.

\section{XCT data analysis}

The reconstructed tomographs were processed using the Dragonfly 3D software, version 3.6.1 (Object Research Systems (ORS) Inc, Montreal, Canada, 2020). No image filters were applied to the reconstructed tomographs. Phases (pits and droplets) were segmented manually based on gray scale values and location. A minimum of eight voxels were necessary to resolve a feature, the resolution of these measurements was $27 \mathrm{\mu m}^{3}$. Because volume measurements were based on manual segmentation some additional measurement uncertainty was present. This measurement uncertainty decreased with increasing pit volume. Measurement uncertainty was $15 \%$ for pits smaller than $4000 \mu^{3}$ and $3 \%$ for pits larger than $10,000 \mu^{3}$, with an approximately linear decrease in measurement uncertainty for volumes between 4000 and $10,000 \mu^{3}$. This was determined by manually segmenting the same feature in different XCT datasets and comparing the volume measurements. Pit depth measurements were $\pm 3.0 \mu \mathrm{m}$.

\section{Post-mortem characterization}

Following the final XCT scan, the plastic tube was removed from the wire to characterize the pits and corrosion product. Corrosion product analysis was performed using reflectance Fourier-transform infrared spectroscopy (FTIR) measurements collected using a Bruker Hyperion IR microscope with a $\times 15$ objective and an $8 \mathrm{~cm}^{-1}$ resolution. Samples were placed under the microscope without further preparation. A knife-edge aperture was used to limit the view to areas of interest on the sample, in this case the corrosion product formed at a pit during the experiment. Recorded sample absorbance data were the result of 32 scan co-averages and were calculated using a background reflectance (128 scan average) from an aluminum sheet.

Xe plasma focused ion beam tool (PFIB) and a Ga soured focused ion beam (FIB) tool were used to cross-section a representative pit. The wire was placed in the Xe PFIB (HyperFIB upgrade to an FEI DB235 Ga Dual beam FIB, 
Applied Beams, LLC, Beaverton, Oregon, USA) and material containing the target pit was cut free from the surrounding material. This was accomplished with an accelerating voltage of $25 \mathrm{kV}$ and a beam current of $1 \mu \mathrm{A}$. The sample was then transferred to an Ga sourced Dual Beam FIB (G2 Helios, FEI, Hillsboro, Oregon, USA) for final sample preparation. The material milled free in the Xe PFIB was lifted-out using standard methods that involved attaching the sample to the micromanipulator tip (Omniprobe 200, Oxford Instruments, Ma, USA). Once attached, the sample was transferred to a standard lift out sample grid using standard lift out methods. The analysis surface was then prepared for SEM and EBSD analysis by careful milling of the sample surface using a $30 \mathrm{kV}$ Ga ion beam at a variety of currents followed by a series of lower voltage ( $5 \mathrm{kV}$ followed by $2 \mathrm{kV}$ ) polishes to produce a surface suitable for EBSD. EBSD data from the microstructure around the pit were collected at $10 \mathrm{kV}$ in a Zeiss Supra 55VP (Zeiss Microscopy, Oberkochen, Germany) using an Oxford Instruments Symmetry EBSD camera and Oxford Aztec EBSD analysis software (Oxford Instruments Nanoanalysis, High Wycombe, UK).

\section{DATA AVAILABILITY}

All relevant data are available from the authors of this paper.

Received: 23 June 2020; Accepted: 24 September 2020;

Published online: 16 October 2020

\section{REFERENCES}

1. Marrow, T. et al. Three dimensional observations and modelling of intergranular stress corrosion cracking in austenitic stainless steel. J. Nucl. Mater. 352, 62-74 (2006).

2. Marrow, T. et al. in Environment-Induced Cracking of Materials 439-447 (Elsevier, 2008).

3. Knight, S. et al. In situ X-ray tomography of intergranular corrosion of 2024 and 7050 aluminium alloys. Corros. Sci. 52, 3855-3860 (2010).

4. Singh, S. et al. In situ investigation of high humidity stress corrosion cracking of 7075 aluminum alloy by three-dimensional (3D) X-ray synchrotron tomography. Mater. Res. Lett. 2, 217-220 (2014).

5. Singh, S. S. et al. Measurement of localized corrosion rates at inclusion particles in AA7075 by in situ three dimensional (3D) X-ray synchrotron tomography. Corros. Sci. 104, 330-335 (2016).

6. Vallabhaneni, R., Stannard, T. J., Kaira, C. S. \& Chawla, N. 3D X-ray microtomography and mechanical characterization of corrosion-induced damage in 7075 aluminium (Al) alloys. Corros. Sci. 139, 97-113 (2018).

7. Liu, X., Frankel, G. S., Zoofan, B. \& Rokhlin, S. In-situ observation of intergranular stress corrosion cracking in AA2024-T3 under constant load conditions. Corros. Sci. 49, 139-148 (2007).

8. Laleh, M. et al. Two and three-dimensional characterisation of localised corrosion affected by lack-of-fusion pores in $316 \mathrm{~L}$ stainless steel produced by selective laser melting. Corros. Sci. 165, 108394 (2020).

9. Ghahari, M. et al. Synchrotron X-ray radiography studies of pitting corrosion of stainless steel: extraction of pit propagation parameters. Corros. Sci. 100, 23-35 (2015).

10. Davenport, A. et al. Mechanistic studies of atmospheric pitting corrosion of stainless steel for ILW containers. Corros. Eng. Sci. Technol. 49, 514-520 (2014).

11. Mohammed-Ali, H. B., Street, S. R., Attallah, M. M. \& Davenport, A. J. Effect of microstructure on the morphology of atmospheric corrosion pits in type $304 \mathrm{~L}$ stainless steel. Corrosion 74, 1373-1384 (2018).

12. Rafla, V. N., King, A. D., Glanvill, S., Davenport, A. \& Scully, J. R. Operando assessment of galvanic corrosion between $\mathrm{Al}-\mathrm{Zn}-\mathrm{Mg}-\mathrm{Cu}$ alloy and a stainless steel fastener using X-ray tomography. Corrosion 74, 5-23 (2018).

13. Singh, S. S., Stannard, T. J., Xiao, X. \& Chawla, N. In situ X-ray microtomography of stress corrosion cracking and corrosion fatigue in aluminum alloys. JOM 69, 1404-1414 (2017).

14. Stannard, T. J. et al. 3D time-resolved observations of corrosion and corrosionfatigue crack initiation and growth in peak-aged Al 7075 using synchrotron X-ray tomography. Corros. Sci. 138, 340-352 (2018).

15. Singh, S. S., Williams, J. J., Xiao, X., De Carlo, F. \& Chawla, N. in Fatigue of Materials II 17-25 (Springer, 2013).

16. Glanvill, S. J. M. Atmospheric Corrosion of AA2024 in Ocean Water Environments (University of Birmingham, 2018).

17. Du Plessis, A. Studies on Atmospheric Corrosion Processes in AA2024 (University of Birmingham, 2015).
18. Knight, S., Salagaras, M. \& Trueman, A. The study of intergranular corrosion in aircraft aluminium alloys using X-ray tomography. Corros. Sci. 53, 727-734 (2011).

19. Risteen, B., Schindelholz, E. \& Kelly, R. Marine aerosol drop size effects on the corrosion behavior of low carbon steel and high purity iron. J. Electrochem. Soc. 161, C580-C586 (2014).

20. Landolfo, R., Cascini, L. \& Portioli, F. Modeling of metal structure corrosion damage: a state of the art report. Sustainability 2, 2163-2175 (2010).

21. Blücher, D. B., Svensson, J.-E. \& Johansson, L.-G. The influence of $\mathrm{CO}_{2}, \mathrm{AlCl}_{3} \cdot 6 \mathrm{H}_{2} \mathrm{O}$ $\mathrm{MgCl}_{2} \cdot 6 \mathrm{H}_{2} \mathrm{O}, \mathrm{Na}_{2} \mathrm{SO}_{4}$ and $\mathrm{NaCl}$ on the atmospheric corrosion of aluminum. Corros. Sci. 48, 1848-1866 (2006).

22. Blücher, D. B., Lindström, R., Svensson, J. \& Johansson, L. The effect of $\mathrm{CO}_{2}$ on the $\mathrm{NaCl}$-induced atmospheric corrosion of aluminum. J. Electrochem. Soc. 148, B127-B131 (2001).

23. Schaller, R. F., Jove-Colon, C. F., Taylor, J. M. \& Schindelholz, E. J. The controlling role of sodium and carbonate on the atmospheric corrosion rate of aluminum. npj Mater. Degrad. 1, 1-8 (2017).

24. Chen, X., Wang, J., Ju, X. \& Wang, X. The role of $\mathrm{Na}+$ in Al surface corrosion studied by single-shot laser-induced breakdown spectroscopy. Appl. Surf. Sci. 501, 144238 (2020).

25. Kuhlmann-Wilsdorf, D. \& Hansen, N. Geometrically necessary, incidental and subgrain boundaries. Scr. Metall. Mater. 25, 1557-1562 (1991).

26. Bay, B., Hansen, N., Hughes, D. A. \& Kuhlmann-Wilsdorf, D. Overview no. 96 evolution of fcc deformation structures in polyslip. Acta Metall. Mater. 40, 205-219 (1992).

27. Kuhlmann-Wilsdorf, D. Dislocation cells, redundant dislocations and the LEDS hypothesis. Scr. Mater. 34, 641-650 (1996).

28. Randle, V., Hansen, N. \& Jensen, D. J. The deformation behaviour of grain boundary regions in polycrystalline aluminium. Philos. Mag. A 73, 265-282 (1996).

29. Hansen, N. \& Jensen, D. J. Development of microstructure in FCC metals during cold work. Philos. Trans. R. Soc. A 357, 1447-1469 (1999).

30. Hansen, N. New discoveries in deformed metals. Metall. Mater. Trans. A 32 2917-2935 (2001).

31. Park, J., Paik, C., Huang, Y. \& Alkire, R. C. Influence of Fe-Rich intermetallic inclusions on pit initiation on aluminum alloys in aerated $\mathrm{NaCl}$. J. Electrochem. Soc. 146, 517 (1999).

32. Ambat, R., Davenport, A. J., Scamans, G. M. \& Afseth, A. Effect of iron-containing intermetallic particles on the corrosion behaviour of aluminium. Corros. Sci. 48 , 3455-3471 (2006).

33. Morton, S. \& Frankel, G. Atmospheric pitting corrosion of AA7075-T6 under evaporating droplets with and without inhibitors. Mater. Corros. 65, 351-361 (2014).

34. Liang, H., Liu, J., Schaller, R. F. \& Asselin, E. A new corrosion mechanism for X100 pipeline steel under oil-covered chloride droplets. Corrosion 74, 947-957 (2018).

35. Tsuru, T., Tamiya, K.-I. \& Nishikata, A. Formation and growth of micro-droplets during the initial stage of atmospheric corrosion. Electrochim. Acta 49, 2709-2715 (2004).

36. Zhang, J., Wang, J. \& Wang, Y. Micro-droplets formation during the deliquescence of salt particles in atmosphere. Corrosion 61, 1167-1172 (2005).

37. Chen, Z. \& Kelly, R. Computational modeling of bounding conditions for pit size on stainless steel in atmospheric environments. J. Electrochem. Soc. 157, C69-C78 (2010).

38. Krouse, D., Laycock, N. \& Padovani, C. Modelling pitting corrosion of stainless steel in atmospheric exposures to chloride containing environments. Corros. Eng. Sci. Technol. 49, 521-528 (2014).

39. Anderko, A., Sridhar, N. \& Dunn, D. A general model for the repassivation potential as a function of multiple aqueous solution species. Corros. Sci. 46 1583-1612 (2004).

40. Sato, N. The stability of localized corrosion. Corros. Sci. 37, 1947-1967 (1995).

41. Frankel, G. The growth of 2-D pits in thin film aluminum. Corros. Sci. 30, 1203-1218 (1990).

42. Baumgärtner, M. \& Kaesche, H. Aluminum pitting in chloride solutions: morphology and pit growth kinetics. Corros. Sci. 31, 231-236 (1990).

43. Lin, P., Aust, K., Palumbo, G. \& Erb, U. Influence of grain boundary character distribution on sensitization and intergranular corrosion of alloy 600 . Scr. Metall. Mater. 33, 1387-1392 (1995).

44. Bałkowiec, A., Michalski, J., Matysiak, H. \& Kurzydlowski, K. Influence of grain boundaries misorientation angle on intergranular corrosion in 2024-T3 aluminium. Mater. Sci. Pol. 29, 305-311 (2011).

45. Cerit, M., Genel, K. \& Eksi, S. Numerical investigation on stress concentration of corrosion pit. Eng. Fail. Anal. 16, 2467-2472 (2009).

46. Cerit, M. Numerical investigation on torsional stress concentration factor at the semi elliptical corrosion pit. Corros. Sci. 67, 225-232 (2013).

47. Chen, G., Wan, K.-C., Gao, M., Wei, R. \& Flournoy, T. Transition from pitting to fatigue crack growth-modeling of corrosion fatigue crack nucleation in a 2024T3 aluminum alloy. Mater. Sci. Eng. A 219, 126-132 (1996). 
48. Huang, Y., Wei, C., Chen, L. \& Li, P. Quantitative correlation between geometric parameters and stress concentration of corrosion pits. Eng. Fail. Anal. 44, 168-178 (2014).

49. International, A. Standard Test Method for Analysis of Aluminum and Aluminum Alloys by Inductively Coupled Plasma Atomic Emission Spectrometry (Performance Based Method) (Standard Designation E3061 - 17, ASTM International, West Conshohocken, $P A$ ).

50. Bachmann, F., Hielscher, R. \& Schaeben, H. in Solid State Phenomena, 63-68.

51. Wright, S. I., Nowell, M. M. \& Field, D. P. A review of strain analysis using electron backscatter diffraction. Microsc. Microanal. 17, 316-329 (2011).

52. Schindelholz, E. \& Kelly, R. Application of inkjet printing for depositing salt prior to atmospheric corrosion testing. Electrochem. Solid-State Lett. 13, C29-C31 (2010).

53. Greenspan, L. Humidity fixed points of binary saturated aqueous solutions. J. Res. Natl Bur. Stand. Sec. A 81, 89-96 (1977).

\section{ACKNOWLEDGEMENTS}

The authors would like to acknowledge James Griego, Jason Taylor, Laura Martin, Kathleen Alam, Luis Jose Jauregui, Dustin Coleman, Renae Hickman, Celedonio Jaramillo, Christina Profazi, Daniel Lee Perry, Joseph Michael, and Rebecca Schaller. Supported by the Laboratory Directed Research and Development program at Sandia National Laboratories, a multimission laboratory managed and operated by National Technology and Engineering Solutions of Sandia LLC, a wholly owned subsidiary of Honeywell International Inc. for the U.S. Department of Energy's National Nuclear Security Administration under contract DE-NA0003525. The views expressed in the article do not necessarily represent the views of the U.S. DOE or the United States Government.

\section{AUTHOR CONTRIBUTIONS}

P.J.N. performed in-situ experiments and analysis of XCT data. M.A.M. performed microscopy of corroded samples. P.J.N., M.A.M., and E.J.S. performed data analysis of microscopy. All authors discussed and contributed to the writing of the paper.

\section{COMPETING INTERESTS}

The authors declare no competing interests.

\section{ADDITIONAL INFORMATION}

Supplementary information is available for this paper at https://doi.org/10.1038/ s41529-020-00136-3.

Correspondence and requests for materials should be addressed to P.J.N.

Reprints and permission information is available at http://www.nature.com/ reprints

Publisher's note Springer Nature remains neutral with regard to jurisdictional claims in published maps and institutional affiliations.

(i) Open Access This article is licensed under a Creative Commons adaptation, distribution and reproduction in any medium or format, as long as you give appropriate credit to the original author(s) and the source, provide a link to the Creative Commons license, and indicate if changes were made. The images or other third party material in this article are included in the article's Creative Commons license, unless indicated otherwise in a credit line to the material. If material is not included in the article's Creative Commons license and your intended use is not permitted by statutory regulation or exceeds the permitted use, you will need to obtain permission directly from the copyright holder. To view a copy of this license, visit http://creativecommons. org/licenses/by/4.0/.

This is a U.S. government work and not under copyright protection in the U.S.; foreign copyright protection may apply 2020 